\title{
Effects of Polypropylene Fiber Content on Strength and Workability Properties of Concrete
}

\author{
Arsalan H. Hasan, Nyazi R. Maroof, Yassin A. Ibrahim* \\ Department of Building and Construction, Erbil Technology Institute, Erbil Polytechnic University, Iraq
}

\author{
${ }^{*}$ Corresponding author: \\ Yassin A. Ibrahim, \\ Department of Building \\ and Construction, Erbil \\ Technology Institute, Erbil \\ Polytechnic University, Iraq. \\ E-mail: Y.ibrahim@gmx.com
}

Received: 30 June 2018

Accepted: 01 March 2019

Published: 10 April 2019

\section{DOI}

10.25156/ptj.v9n1y2019.pp7-12

\section{A B S T R A C T}

Low tensile strength of plain concrete is due to the inherent presence of microcracks due to drying shrinkage occurrences or other causes of volume changes in concrete. The addition of a proper amount of fibers to concrete would act as crack arrester thus improves its static or dynamic properties. In this paper, the concrete with different amount of polypropylene fiber was investigating to find out the fibers effect on its fresh and mature properties. A plain concrete mix (reference mix) prepared for comparison purposes. Nine concrete mixes were prepared with different fiber volume fraction (FVF) ranging from $0.06 \%$ to $2.16 \%$. It has been found out that the fiber content of the concrete mix will increase compressive, splitting, and flexural strengths of the concrete at the age of 28 days. The strengths increased and reached their maximum value at a corresponding (FVF) of about $0.36 \%$. In comparison with the reference mix, the increase in the maximum compressive strength was about $18 \%$, while the increase in maximum splitting tensile strength was about $16 \%$ and the increase in flexural strength was about $14 \%$. When the fiber content increased beyond the mentioned $0.36 \%$ volume fraction: The concrete strengths started to decrease due to high volume fiber interface with the cohesiveness of the concrete matrix causing difficulty in concrete compaction with lowering its workability. At fiber (FVF) of $0.96 \%$, the concrete slump value became zero. Thus, forced vibration needed for the compaction. For each mature concrete mix density and water absorption percentage were measured. It has been noticed that with an increase of fiber dosage in the concrete mix its density will decrease leading to contrarily an increase in the water absorption percentage. This was due to an increase in air void in the concrete due to the reduction in the workability of the concrete.

Keywords: Compressive strength; Flexural strength; Polypropylene fiber; Reference mix; Splitting tensile strength

\section{INTRODUCTION}

Low tensile strength and brittleness of plain concrete are due to the inherent presence of microcracks in it. The cracks progress even before loading the concrete caused by the volume change due to drying shrinkage. When the concrete is subjected to load, the microcracks propagate and open up due to the effect of stress concentration, further cracks form in places of minor defects. The underdeveloped structural cracks proceed slowly; fluctuate in direction bypassing the obstacles and more resistant grains in the matrix. The progress of such microcracks is the main cause of inelastic deformations in concrete. It has been recognized that substantial improvement occurs in concretes static and dynamic properties by the addition of small, narrowly spaced, and uniformly dispersed fibers to concrete and it would act as crack arrester. This type of concrete is known as fiber reinforced concrete (FRC) (Shetty, 2005) and Domone and Illston, 2010.
These factors affect properties of fiber reinforced concrete:

1. Relative fiber matrix stiffness: The modulus of elasticity of fiber must be much higher than that of the matrix for efficient stress transmission.

2. Volume fraction of fibers: The strength of the composite largely depends on the amount of fibers used in it. The increase in the volume of fibers, increase approximately linearly, the tensile strength and toughness of the composite (Shah and Rangan, 1971). Use of a greater percentage of fiber is likely to cause balling and severity of concrete and mortar.

3. Aspect ratio of the Fiber: Increase in the aspect ratio increases the ultimate strength of the concrete linearly. It has been reported that aspect ratio past 75 causes relative strength and toughness to reduce.

4. Orientation of fibers: The fibers arranged parallel to the applied load offered extra tensile strength and toughness than arbitrarily dispersed or perpendicular fibers.

5. Workability and compaction of concrete: At certain fiber volume fraction (FVF), the workability of 
concrete considerably declines. This situation adversely distresses the consolidation of the fresh mix. Even prolonged external vibration fails to compact the concrete.

6. Size of coarse aggregate: Based on investigations maximum size of the coarse aggregate should be restricted to $10 \mathrm{~mm}$, to avoid appreciable lessening in the strength of the composite (Shetty, 2005).

7. Bonding: Three types of bond are available in FRC:

i. Elastic bonding - due to adherence of the fibers to the matrix.

ii. Frictional bonding - the resistance to pull-out of the fiber caused by friction between the fibers and the matrix.

iii. Mechanical bonding - the interlocking of the fibers within the matrix causes the fiber deform along their length.

Frictional bonding dominates the important part of FRC stress-strain behavior the post-cracking region and so is of most interest. Pull-out tests are used to estimate the frictional bond. These are difficult to interpret, usual values for the average bond stress in monofilament FRC with smooth cylindrical fibers are around $0.1,0.5$, and 1 $\mathrm{MPa}$ for polyethylene (PE), polypropylene, and steel fibers, respectively. Typical reported values of bonding stress are around 0.6 $\mathrm{MPa}$ for carbon, and 0.5-1 $\mathrm{MPa}$ for fresh and aged glass-FRC, respectively (Bentur and Mindess, 1990); (Bentur and Mindess, 2007); (Horne et al., 2007); and (Purnell et al., 2000).

\section{PREVIOUS STUDIES}

The strength potential of nylon-fiber-reinforced concrete examined versus the polypropylene-fiber-reinforced concrete at a fiber content of $0.6 \mathrm{~kg} / \mathrm{m}^{3}$. The compressive and splitting tensile strengths and modulus of rupture of the nylon fiber concrete improved by $6.3 \%, 6.7 \%$, and $4.3 \%$, respectively, over those of the polypropylene fiber concrete. On the influence resistance, the first crack and failure strengths and the percentage rises in the post first crack blow enhanced more for the nylon fiber concrete than for its polypropylene counterpart. In accumulation, the shrinkage crack reduction potential also developed more for the nylon - fiber -reinforced mortar (Song et al., 2005).

Two different concrete design strengths (medium and high) studied with varying amounts and kinds of polypropylene fiber fraction/volume to create a common link between fiber additions and reduced final compressive strength. The findings from the test program indicated a linear reduction in strength, which was observed as being directly connected to fiber inclusion in concrete. Density was also found to be condensed with the addition of fibers to a similar degree to that of air entrainment (Richardson, 2006).

The basalt fiber is a promising reinforcing fiber because it has a relatively higher tensile strength and a density alike to that of a concrete matrix as well as no corrosion possibility. Single fiber pulls out tests were performing and then the tensile strength of fiber measured according to fiber orientation. The test results indicated that basalt fiber has a strong chemical bond with the cementitious matrix, 1.88 times greater than that of polyvinyl alcohol fibers with it. However, other properties of basalt fiber such as sliphardening coefficient and strength reduction coefficient were worse than polyvinyl alcohol and PE fibers in terms of fiber bridging capacity (Song et al., 2005).

By increasing the content of polypropylene fibers materials, the ductility of concrete significantly increased and maximum compressive strength somewhat increased. Further escalation of polypropylene fibers (higher values than $0.5 \mathrm{vol} . \%$ ) did not rise the ultimate bond strength, but it provided much more ductile bond behavior. Besides, the addition of polypropylene fibers caused a significant increase in the percentage of water absorption for the tested concrete specimens (Mohamed, 2006).

Dyneema fiber added to the concrete mix and caused its slump value to drop and reduce the workability. For this reason, the $\mathrm{AE}$ water reducing added to the concrete mix to improve its workability also to increase the compressive strength. It has concluded that the best positive effect has obtained when $1.5 \%$ volume fraction of Dyneema fiber used in the mix (Chen, 2012).

Marble dust has used as a replacement for sand in conventional concrete, which was highly efficient in increasing the strength without affecting its properties in the fresh and hardened state. The concrete mix has adopted for partial replacement of sand with marble dust. Marble dusts were added at $10 \%, 20 \%, 30 \%, 40 \%$, and $50 \%$. PE fiber was added to the concrete in $0.2 \%, 0.4 \%, 0.6 \%, 0.8 \%$, and $1 \%$. The results of the investigational work showed that replacement of marble dust with PE fiber increase, up to $6 \%$ for compressive strength, and up to $8 \%$ for split tensile strength and flexural strength of concrete (Amudhavalli and Thilaga, 2017).

The inclusion of $0.1 \%$ fiber gave minor reduction $(2 \%)$ in compressive strength while the tensile strength increased by $39 \%$ with same fiber content compared to the plain concrete. The experimental result with the inclusion of $0.1-0.3 \%$ fiber in concrete indicated that plastic shrinkage cracks were lowered by $50-99 \%$ compared to the plain concrete. For reference concrete (without fiber), test within 
the high temperature and controlled humidity chamber gave higher crack width than the acceptable limit $(3 \mathrm{~mm})$ specified by the ACI 224 . With the inclusion of $0.1 \%$ fiber reduced the crack width down to $1 \mathrm{~mm}$ and the trend was continued with the addition of more fibers. However, results disclosed that with the addition of polypropylene fiber both water and gas permeability coefficient was increased (Sadiqul et al., 2016).

An ultra-high-performance mortar (UHPM) reinforced by micro steel fiber of $1.5 \mathrm{vol} . \%$ and the UHPM reinforced by PE fibers with three unalike fiber contents were designed and prepared. A series of experiments were undertaken to assess the influence of PE fiberfiber on the properties of the UHPM. The results initiate a lower strength level, higher tensile strain capacity, and toughness, and larger crack width in the PE fiber-reinforced UHPM compared to micro steel fiber-reinforced UHPM. It was also demonstrated that tensile strain capacity and toughness of $4.05 \%$ and $0.454 \mathrm{MPam} / \mathrm{m}$, respectively, could be attained when using the proposed PE-fiber-reinforced UHPM (Choi et al., 2017).

This research is to investigate the effect of the addition of different volume crack of polypropylene fibers to concrete to improve its performances in its fresh and hard conditions. The effect of the addition of polypropylene fibers on the mechanical properties of normal strength concrete is studied. The polypropylene fibers were added at different concentration starting from $0.06,0.0 .12,0.24,0.48,0.72,0.96,1.2,1.44,168$, 1.92 , and $2.16 \%$, respectively, by volume. Slump value was measured for the fresh concrete and compression, splitting and bending tests were carried out on the mature concrete to find the mechanical properties such as maximum compressive strength, splitting strength, and flexural strength. The percentage of absorption and density of each concrete mix was determined for comparison between the mixes.

\section{EXPERIMENTAL WORK}

\section{Materials}

The material used in this study was a local ordinary Portland cement produced by MASS factory, local coarse aggregate with a maximum size of $12.5 \mathrm{~mm}$, and local fine aggregate with a 3.28 fineness modulus and Polypropylene fibers with a (12 mm length, $0.032 \mathrm{~mm}$ diameter, $900 \mathrm{~kg} / \mathrm{m}^{3}$ density, and $650 \mathrm{MPa}$ tensile strength) as shown in Figure 1. The source of water was from the tap water supply. The initial test specimens which were free from polypropylene fibers (no-fiber mix) were prepared as a base for comparison. Details of all concrete mixes are giving in Table 1. The determination of workability of the fresh concrete, slump tests were conducted in accordance with the ASTM C 134.

\section{Mixing and Curing}

Dry aggregates were mixed for $1 \mathrm{~min}$ in drum mixer. Then, the specified amount of polypropylene fiber with half of the mix-water was added and mixed for another $3 \mathrm{~min}$. After that, the cement and the remaining half of the mix-water were added thus all the constituents mixed for further 2 min according to ASTM C 192-81. Then, the fresh

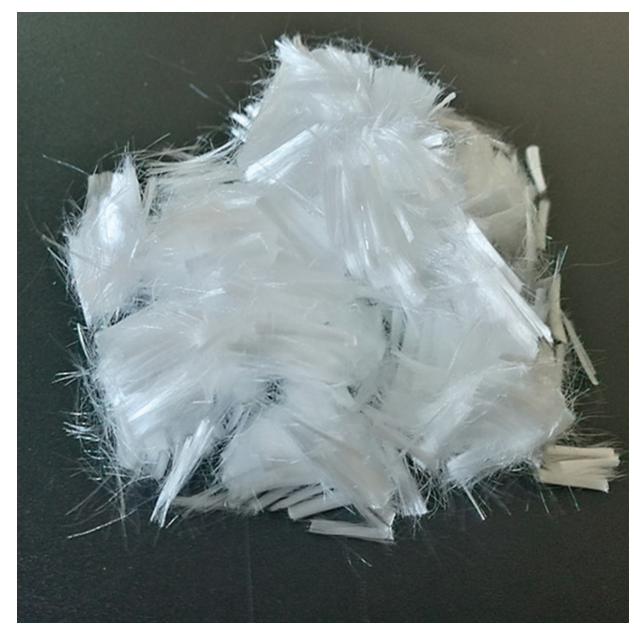

Figure 1: Polypropylene fiber

Table 1: Details of concrete mixes

\begin{tabular}{lcccccc}
\hline Mix no & Slump $(\mathrm{mm})$ & Cement $\left(\mathbf{k g} / \mathbf{m}^{3}\right)$ & Sand $\left(\mathbf{k g} / \mathbf{m}^{3}\right)$ & Gravel $\left(\mathbf{k g} / \mathbf{m}^{3}\right)$ & W/C ratio & Polypropylene fiber volume fraction \% \\
\hline 1 & 40 & 395 & 593 & 1185 & 0.45 & 0 \\
2 & 30 & 395 & 593 & 1185 & 0.45 & 0.06 \\
3 & 30 & 395 & 593 & 1185 & 0.45 & 0.12 \\
4 & 15 & 395 & 593 & 1185 & 0.45 & 0.24 \\
5 & 15 & 395 & 593 & 1185 & 0.45 & 0.48 \\
6 & 8 & 395 & 593 & 1185 & 0.45 & 0.72 \\
7 & 0 & 395 & 593 & 1185 & 0.45 & 0.96 \\
8 & 0 & 395 & 593 & 1185 & 0.45 & 1.2 \\
9 & 0 & 395 & 593 & 1185 & 0.45 & 1.44 \\
10 & 0 & 395 & 593 & 1185 & 0.45 & 1.68 \\
11 & 0 & 395 & 593 & 1185 & 0.45 & \\
12 & 0 & 395 & 593 & 1185 & 0.45 & 2.16 \\
\hline
\end{tabular}


concrete poured into the molds in three layers, and each layer of the mix compacted using a mechanical vibrator. After $24 \mathrm{~h}$, the molds were opened that the specimens were put in curing tank at a temperature of $21^{\circ}$ until test time.

\section{Test Methods}

The water absorption tests were carried out on 100-mm cubic specimens in accordance with BS 1881-122. ASTM C 39 test method was used to determine the compressive strength of $100-\mathrm{mm}$ cubic specimens using a hydraulic testing machine. To measure the splitting tensile strength, ASTM C 496 test method was used on (100 mm*200 mm) cylindrical specimens. The flexural strength test was performed using concrete prisms with dimensions $(100 \mathrm{~mm} * 100 \mathrm{~mm} * 400 \mathrm{~mm})$ under third- point loading, according to ASTM C 78-02. Figure 2 shows the setup used for the flexural tests.

\section{RESULTS AND DISCUSSION}

\section{Compressive Strength}

It can be seen in Figure 3 that the polypropylene fiber will affect the concrete mix by increasing its 28 days' compressive strength and it reaches to a maximum value of $46 \mathrm{MPa}$ at FVF of about $0.36 \%$, which is about $18 \%$ increase with respect of compression strength of the no-fiber mix. The strength starts to decrease when the amount of fiber contents is increased further because higher volumes of fibers interfere with the cohesiveness of the concrete matrix.

\section{Tensile Strength}

The tensile strength of concrete is only 10\% of its compressive strength. It is clear that the addition of fibers to a concrete mixture is beneficial to the tensile properties of concrete. The fibers act as crack arresters in the concrete matrix prohibiting the propagation of cracks in the plastic and hardened states (Ahmed et al., 2006).

According to Figure 4, the tensile strength starts to increase with the increasing of the volume fraction of fiber content thus reaches the maximum value of $4 \mathrm{MPa}$ at fiber content about $0.36 \%$ which is about $16 \%$ with a comparison to the tensile strength of reference mix. The key to success in achieving strength seems to lie on two points, fibers must be uniformly distributed in the mix, and fiber proportion must be carefully selected. The tensile strength is increased due to a bridging mechanism of polypropylene fibers, and after volume fraction $0.36 \%$ the extra fiber in the concrete causes a reduction in the bond strength between concrete ingredients so results in quick failure as compared to concrete with less volumes of fibers (Ahmed et al., 2006).

\section{Flexural Strength}

The behavior of polypropylene fiber reinforced concrete in flexure strength seems to be similar to that in tensile strength; the maximum value of $5.1 \mathrm{MPa}$ is obtained at FVF of about $0.36 \%$ which is about $14 \%$ increase with respect to the flexural strength of no-fiber mix. Again, the flexural strength starts to decrease when the dosage of the fiber content of the mix is increased further as its shown in Figure 5.

\section{Density and Absorption}

The density of the polypropylene fiber concrete after 28 days of curing is summarized in Figure 6. The concrete without polypropylene fiber exhibits the highest density value of $2433 \mathrm{~kg} / \mathrm{m}^{3}$. While the concrete with $2.16 \%$ polypropylene fiber content has the lowest

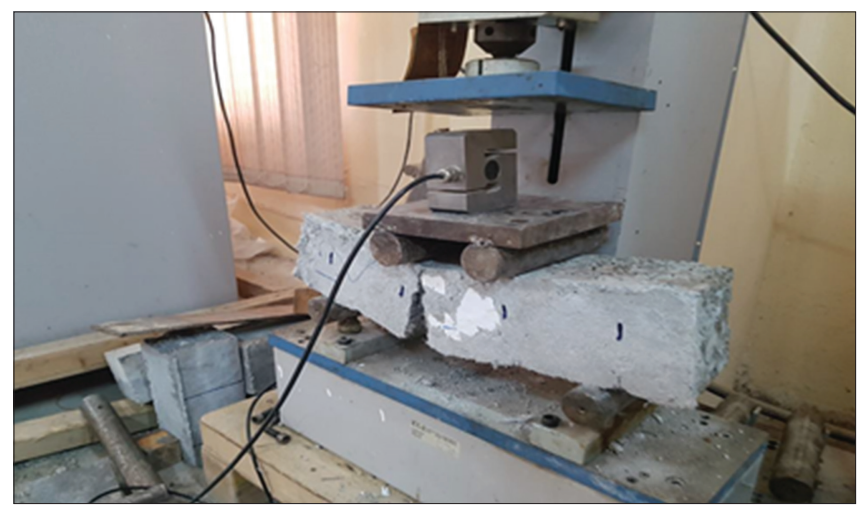

Figure 2: Flexural sample setup

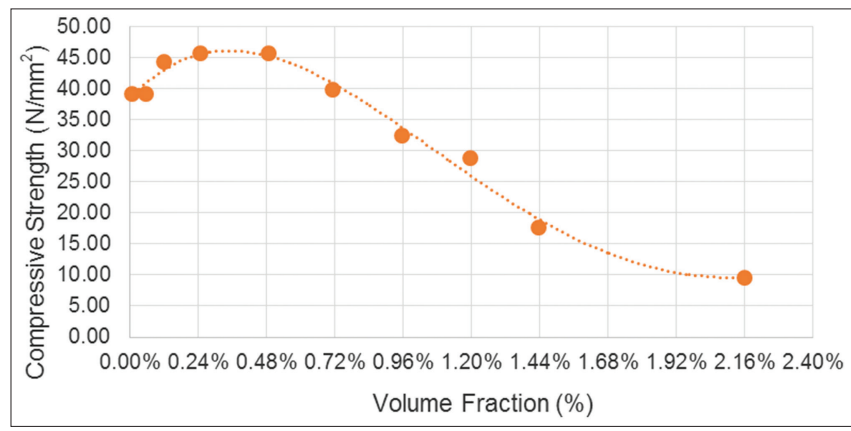

Figure 3: Compressive strength of polypropylene fiber concrete

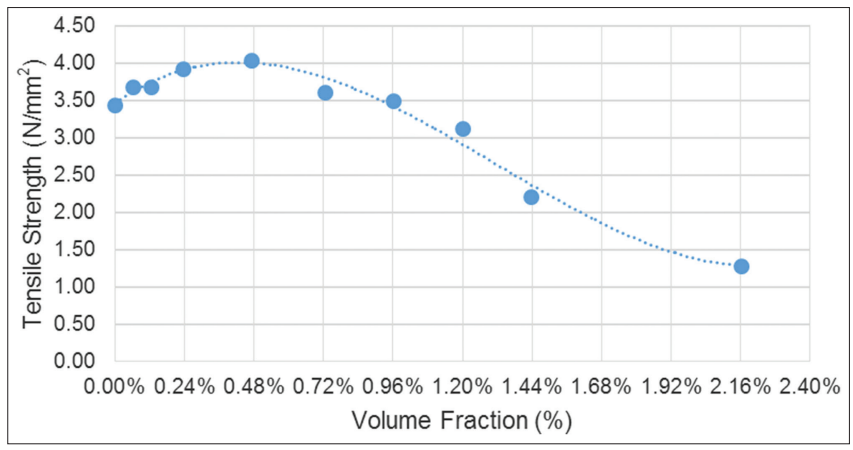

Figure 4: Tensile strength of polypropylene fiber concrete 


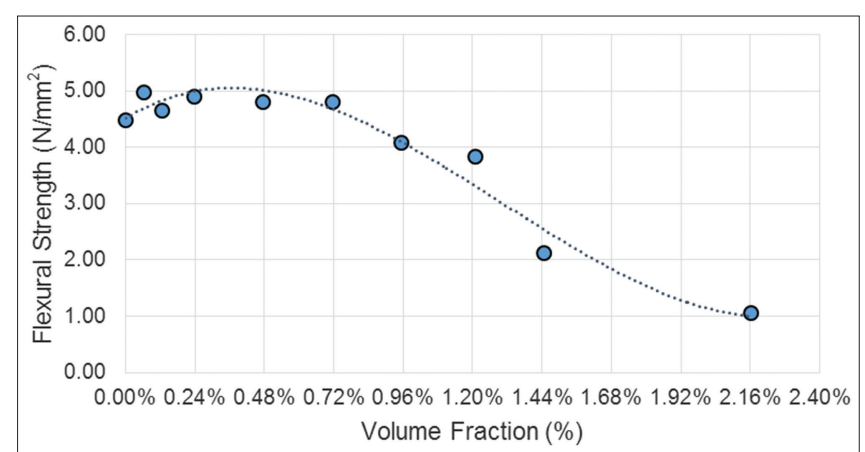

Figure 5: Flexural strength of polypropylene fiber concrete

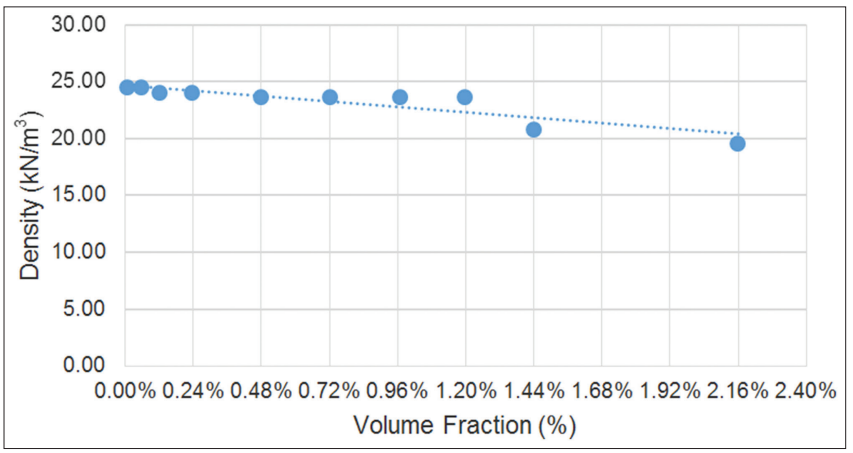

Figure 6: Density of polypropylene fiber concrete

value $1969 \mathrm{~kg} / \mathrm{m}^{3}$ of density. In term of polypropylene fiber content, the value of density decreases with the increase of polypropylene fiber content (Aggarwal, 1995).

Water absorption results for concrete after 28 days of curing are presented in Figure 7. Water absorption increases with the increased volume fraction percent of polypropylene fiber. The highest value of water absorption of the concrete is $4.96 \%$ when the FVF reaches to $2.16 \%$. The reason is that with an increase of an amount of polypropylene fiber in the concrete the degree of compaction of the mix reduces thus the volume of air void in the concrete increases causing its water absorption to increase and its density to reduce at a mature state of the concrete.

\section{Slump Test}

The slump value of the no-fiber concrete was about $40 \mathrm{~mm}$ while the slump value of the first fiber concrete mix with $0.06 \%$ volume fraction reduced to $30 \mathrm{~mm}$. Then, the slump started to decrease to $0 \mathrm{~mm}$ as FVF reached to $0.96 \%$ and the concrete kept with zero slump when the fiber content increased furthers, Figure 8. This is due to decrease in the workability of the concrete with an increase of FVF in the mix that is due to the large creation of frictional resistance between polypropylene fibers and the concrete particles (McWhannell, 1994).

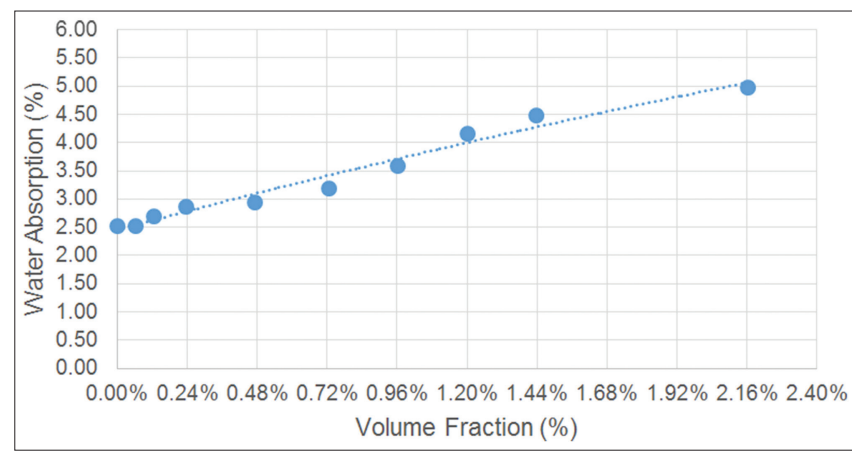

Figure 7: Water absorption of polypropylene fiber concrete

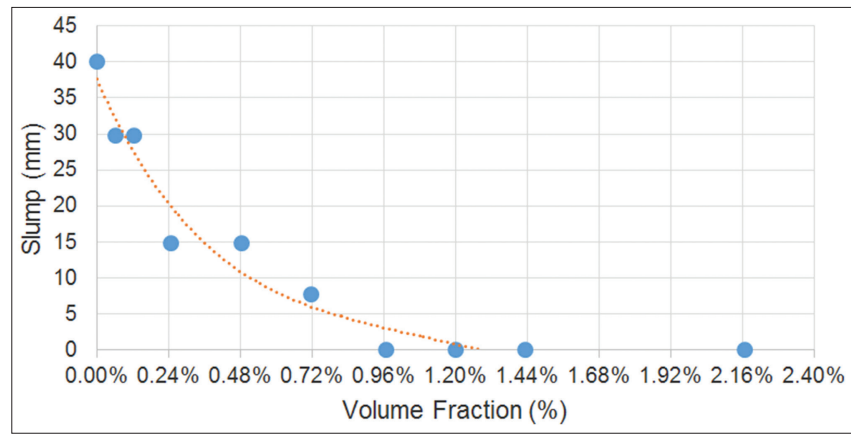

Figure 8: Slump of polypropylene fiber concrete against volume fraction

\section{CONCLUSIONS}

The addition of polypropylene fiber to concrete mix causes an improvement in 28 days strength properties of the concrete mix. The maximum compressive strength was obtained when the FVF in the concrete was about $0.36 \%$. Similarly, the splitting tensile strength and the flexural strength of the concrete were attained their maximum value at the same corresponding FVF. With respect to the strength of the plain concrete mix, the increase in the maximum compressive strength, the maximum splitting tensile strength, and the maximum flexure strength were about $18 \%, 16 \%$, and $14 \%$, respectively.

The strength of the concrete mixes starts to decrease when the FVF in the mix increased further than $0.36 \%$ due to the high volume of fiber interface with the cohesiveness of the concrete matrix and difficulties in the concrete compaction. With the addition of FVF to fresh concrete mix caused the workability of the concrete to reduce accordingly. The concrete slump value approached to zero when its fiber content was reached to $0.96 \%$.

Eventually, when the amount of fibre (volume fraction) increased in the concrete, the exertion in the compaction arises as a result of the amount of air void in the mature concrete mixes became higher thus a linear decrease in the 
concrete density and increase in water absorption were occurred.

\section{REFERENCES}

Aggarwal, L. 1995. Bagasse-reinforced cement composites. Cem. Concr. Compos. 17: 107-112.

Ahmed, S., I. A. Bukhari, J. I. Siddiqui and S. A. A. Qureshi. 2006. A Study on Properties of Polypropylene Fiber Reinforced Concrete. $31^{\text {st }}$ Conference on our World in Concrete and Structures, Singapore. p16-17.

Amudhavalli, N. K. and T. Thilaga. 2017. Utilization of marble dust in polyethylene fiber reinforced concrete. Int. J. Civil Eng. 4: 15-17.

Bentur, A. and S. Mindess. 1990. Fibre Reinforced Cementitious Composites. Elsevier Science Publishers, United Kindom.

Bentur, A. and S. Mindess. 2007. Fibre Reinforced Cementitious Composites. Taylor and Francis, London.

Chen, Y. S. 2012. Research for Polyethylene Fibers Reinforced Concrete.

Choi, J. I., S. Y. Jang, S. J. Kwon and B. Y. Lee. 2017. Tensile behavior and cracking pattern of an ultra-high performance mortar reinforced by polyethylene fiber. Adv. Mater. Sci. Eng. 2017: 1-10.

Domone, P. and J. Illston. 2010. Construction Materials: Their Nature and Behaviour. CRC Press, United States.
Horne, A., I. Richardson and R. Brydson. 2007. Quantitative analysis of the microstructure of interfaces in steel reinforced concrete. Cem. Concr. Res. 37: 1613-1623.

Mcwhannell, G. 1994. The Effects of Polypropylene Fibres in Fresh Concrete. $5^{\text {th }}$ International RILEM Symposium on Self Compacting Concrete, Belgium. p99-106.

Mohamed, R. 2006. Effect of polypropylene fibers on the mechanical properties of normal concrete. J. Eng. Sci. Assiut Univ. 34: 10491059.

Purnell, P., A. Buchanan, N. Short, C. Page and A. Majumdar. 2000. Determination of bond strength in glass fibre reinforced cement using petrography and image analysis. J. Mater. Sci. 35: 4653-4659.

Richardson, A. E. 2006. Compressive strength of concrete with polypropylene fibre additions. Struct. Surv. 24: 138-153.

Sadiqul, I. G. M. and S. D. Gupta. 2016. Evaluating plastic shrinkage and permeability of polypropylene fiber reinforced concrete. Int. J. Sustain. Built Environ. 5: 345-354.

Shah, S. P. and B. V. Rangan. 1971. Fiber reinforced concrete properties. J. Proc. 126-137.

Shetty, M. 2005. Concrete Technology Theory and Practice. Published by S. Chand and Company, Ram Nagar, New Delhi.

Song, P., S. Hwang. and B. Sheu. 2005. Strength properties of nylonand polypropylene-fiber-reinforced concretes. Cem. Concr. Res. 35: 1546-1550. 